\title{
Mobile radiation dosimeter for monitoring of total radiation on-board of civilian aircraft
}

\author{
Vladimir Elin \\ Intersoft Eurasia Corporation, \\ Moscow, Russia \\ Email: elin@intersofteurasia.ru
}

\section{Olga Sharts*}

California Innovations Corp. and Fluorotronics, Inc.

San Diego, CA, USA

Email: olgasharts@gmail.com

*Corresponding author

\section{Michail Merkin}

Laboratory of Detector Systems and Electronics, Skobeltsyn's Research Institute of Nuclear Physics, Moscow State University,

Moscow, Russia

Email: michael.merkin@gmail.com

\begin{abstract}
This paper describes a novel radiation dosimeter technology 'DO-RA' and its uses in commercial flights as 'DO-RA.AVIA' semiconductor module incorporated into smartphones and other electronic devices. We discuss issues of radiation exposure during flights, including possible health risks, and provide an example of experimental data regarding radiation exposure during particular flight, taken recently during 2-hour flights within Russia and in France, which can open reader's eyes to the potential impact of ionising radiation that occurs during the air flights. The article describes 'DO-RA' radiation measurement technology features and functions, demonstrates uses of 'DO-RA.AVIA' radiation measurement module for use in-flight of commercial aircraft. The article suggests more features and uses of 'DO-RA' technology for drug-discovery in-house use, outdoor applications, surveillance and as a gadget for automobiles' gadget.
\end{abstract}

Keywords: radiation semiconductor dosimeter; radiation safety, ionising radiation; in-flight radiation dose; space radiation; 'DO-RA' technology; 'DO-RA.AVIA' module, effective dose; total radiation.

Reference to this paper should be made as follows: Elin, V., Sharts, O. and Merkin, M. (2019) 'Mobile radiation dosimeter for monitoring of total radiation on-board of civilian aircraft', Int. J. Nuclear Safety and Security, Vol. 1, No. 1, pp.64-84.

Biographical notes: Vladimir Elin is CEO \& Founder of Intersoft Eurasia company (2011-current), Moscow, Russia; CEO \& Founder of Smart Logistics Group (2011-current), Moscow, Russia; and Partner, California Innovations Corp. (2017-current), San Diego, CA, USA. In 1995, he and his partners 
established EMSTS Corporation ('Integrated International System of Customs Warehouses') where he served as a President. He obtained his Doctor of Science degree $(\mathrm{PhD})$ in Radio Engineering in 1988 from Bauman's State Technical Academy. He is an author of more than 20 research papers and inventions in the areas of interdisciplinary sciences such as electronics and medical sciences.

Olga Sharts is President/Founder, Chairperson of California Innovations Corp. and Fluorotronics, Inc. (San Diego, California). She is an internationally recognised Raman, FluoroAnalytics and technology expert. She has experience of 20 years in technology development, management and innovations. She acted as a consultant for Siltech, San Jose, CA; General Atomics, San Diego, $\mathrm{CA}$ and Californiamart, Los Angeles, CA; and served as a State Patent Examiner for USSR Patent Office and as a Senior Research Engineer for Rare Metals and Semiconductors R\&D Institute, Moscow. She obtained MSc degree in Chemistry from SDSU (2000) and MSc degree in Chemical Engineering from Moscow State Technical Academy (1982).

Michail Merkin serves as Physics \& Optics Engineer at Intersoft Eurasia company, Moscow, Russia. He is a product engineer for DO-RA technology systems. He is a Head of Laboratory of Detector Systems and Electronics at Skobeltsyn's Research Institute of Nuclear Physics at Moscow State University. His expertise includes modernisation of Si-tracking system, Experiment CLAS12 (JLAB, Newport News, VA), Experiment LHCb (CERN, Geneva), Tracking System in Experiment CBMb (GSI, Germany), RU Space Program Experiment "NUCLEON", RU Accelerator Experiment CVD-2, detector development for SiW system in Experiment Phenix (BNL, USA). He holds PhD in Physics \& Mathematics, Tbilisi State University (1988).

\section{Introduction}

Interaction with the internet of things became much convenient and accessible for consumers after development of various innovative technology products and software which take into consideration the individual demands of consumers.

Our group has developed a patented innovative technology named "DO-RA" and an associated family of products and software which can be used as an aircraft on-board system for monitoring of cosmic ionising radiation exposure of the flight crew and passengers during their flight.

It is well known that commercial aircraft cruise at the altitudes of $10-12 \mathrm{~km}$ above the ground. During these flights, air passengers and flight personnel are exposed to space ionising radiation. Often the level of space ionising radiation (dose of radiation) significantly exceeds the allowed norms for radiation exposure at those heights. As a result, passengers, especially frequent flyers and aviation personnel possibly get an excessive total radiation exposure which may have dangerous long-term impact on their health.

Our article will allow respectful readers to understand their possible risks by taking frequent flights and to possibly take preventive measures such as better travel planning to minimise the damage to their health by a possible total radiation exposure during their commercial flight.

This article can be helpful for professional staff and management of airlines, travel agencies, aviation companies and members of the aviation and airspace industries who 
would acquire knowledge of evolving innovative technology to allow for (i) more protective health management and (ii) corresponding better and smarter rotation of inflight crew, and (iii) better (smarter) care for airlines passengers.

\section{The problem of space (cosmic) radiation}

When getting on board commercial aircraft, people usually do not think that something may pose any danger during their flight except possible thunderstorms or turbulence zones within the standard flight corridor of the civil aviation - altitudes of 10-12 km.

Figure 1 On-board a commercial aircraft

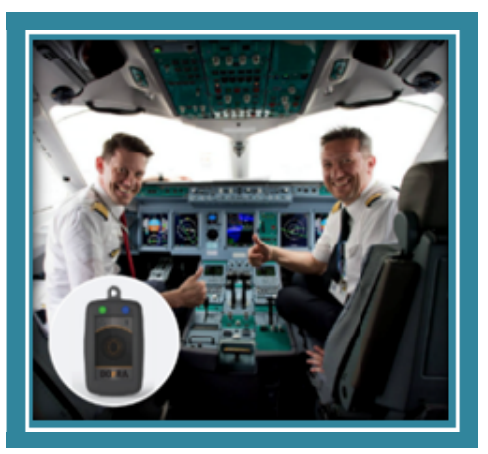

At the end of the last century, civil aviation mostly used lower corridors for the flights at altitudes of 6-8 km above the ground surface. But the modern environmental challenges regarding reduction of the noise due to aircraft engines, emissions, as well as fuel economy per flight mile, made airline pilots to fly much higher, "closer to the stars".

\subsection{Cosmic rays and solar radiation}

It is known that cosmic radiation (space radiation) is an ionising radiation continuously falling on the surface of the Earth from the outer space. It is formed in the Earth's atmosphere because of the interaction between air components' atoms.

There are two types of the cosmic rays - primary and secondary. Primary Cosmic Radiation (CR-1) is a stream of elementary particles that fall on the Earth's surface from space. It occurs due to the eruption and evaporation of matter from the surface of stars and nebula of space.

CR-1 consists of protons (92\%), alpha particles (7\%), isotopes of lithium, beryllium, boron, carbon, nitrogen, oxygen, etc. (1\%). CR-1 is characterised by high penetrating ability.

Furthermore, cosmic radiation has been classified into the following types by origin: (i) extragalactic, (ii) galactic and (iii) solar.

Most of the primary cosmic radiation occurs within our Galaxy, its energy is extremely high - up to $10^{19} \mathrm{eV}$. 
Solar radiation occurs mainly in the form of solar flares, which happen within Sun's 11-year solar cycle. Its energy does not exceed $40 \mathrm{MeV}$. This does not lead to a noticeable increase in the radiation dose level on the Earth's surface.

The average energy of cosmic rays is $10^{10} \mathrm{eV}$, so they are detrimental to any living thing. The atmosphere serves as a kind of shield that protects biological objects from the effects of cosmic particles, and only a few particles can reach the surface of the Earth.

The interaction of cosmic particles with atoms of elements in the atmosphere generates Secondary Cosmic Radiation (CR-2). It consists of mesons, electrons, positrons, protons, neutrons, gamma quanta, i.e. almost all currently known particles.

Figure 2 Effective radiation dose rate depending on the altitude

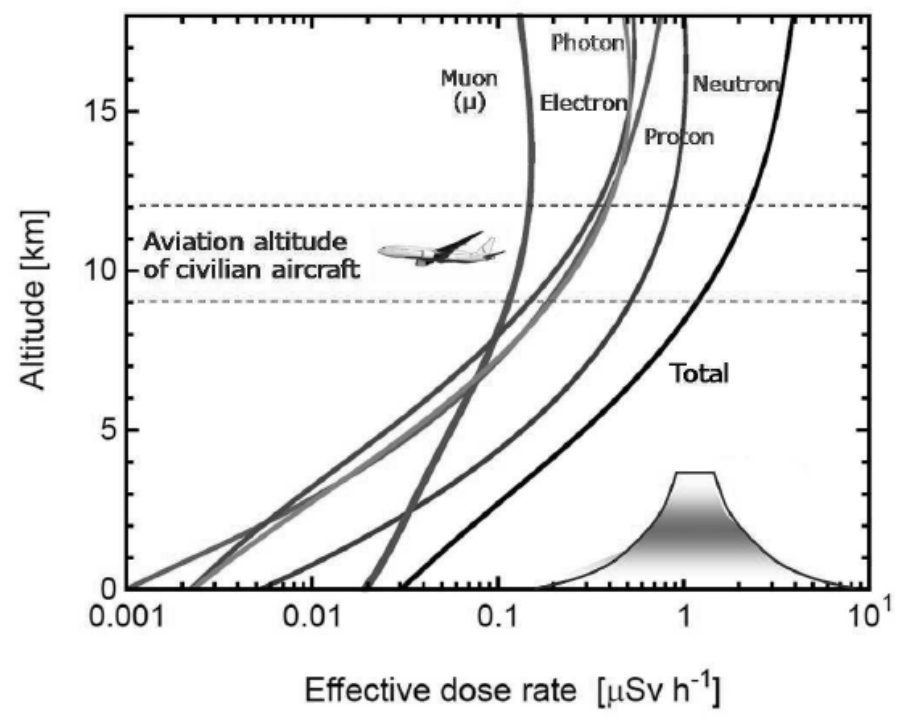

Primary cosmic rays burst into the atmosphere and gradually lose their energy, wasting it on numerous collisions with nucleus of air components' atoms. As a result, we get the fragments, acquiring part of the primary particle's energy. These fragments become factors of ionisation, which destroy and ionise other atoms of the air gases, in other words, they turn into CR-2 particles.

CR-2 arises because of electron-photon and electron-nuclear interactions. In the electron-photon process, the charged particle interacts with the field of the atom's nucleus, generating photons that form pairs of electrons and positrons. These particles, in turn, cause the appearance of new photons. The electron-nuclear process is caused by the interaction of primary particles with the nucleus of air component's atoms whose energy is not less than $3 \times 10^{9} \mathrm{eV}$. Several new particles (mesons, protons, neutrons) appear because of this interaction.

CR-2 reaches its maximum level at the altitude of $20-30 \mathrm{~km}$, at the lower altitudes the processes of CR-2 absorption prevail over the processes of its formation.

The intensity of cosmic radiation depends on the latitude and altitude. Since the cosmic rays are mainly charged particles, they deviate in a magnetic field in the area above the Equator and gathered in the form of craters in the poles areas. Only particles with low energy can reach the Earth's surface in the polar regions (no need to overcome 
the magnetic field). Therefore, the intensity of cosmic radiation at the poles increases due to these rays. In the Equatorial region, only particles that have maximum energies can overcome the deflection effect of the magnetic field and reach the surface.

The average dose rate of cosmic radiation for the Earth's inhabitants is approximately $0.3 \mathrm{mSv}$ per year, but on route, for instance, "Moscow-London-New York" it reaches 0.5 $\mathrm{mSv}$ per year.

We would like to refer reader to an article (Morozova et al., 2014) where they describe in detail all the aspects regarding ionising cosmic radiation.

\subsection{Units for measurement of ionising radiation}

\subsubsection{Equivalent dose}

REM - is the roentgen equivalent man (in some sources - RAD radiation absorbed dose).

It is a unit of equivalent dose, effective dose, and committed dose which may cause health effect in human because of his or her exposure to certain levels of ionising radiation.

Generally,

$1 \mathrm{REM}=1 \mathrm{RAD} * K=100 \mathrm{erg} / \mathrm{g} * K=0.01$ Gray $* K=0.01 \mathrm{~J} / \mathrm{kg} * K=0.01$ Sievert (1)

At the coefficient of radiation quality $K=1$, that is, for $\mathrm{x}$-ray, gamma $(\gamma)$, beta $(\beta)$ radiation, electrons and positrons, 1 REM corresponds to the "equivalent dose of 1 RAD".

The following fact should be particularly noted: back in the '50s it was found that if the exposure dose in $1 \mathrm{Xu}$ air absorbs 83.8-88.0 erg/g (physical equivalent of $\mathrm{x}$-ray), the biological tissue absorbs 93-95 erg/g (biological equivalent of x-ray). Therefore, it appeared that regarding evaluation of obtained radiation dose one can consider (with minimal error) the following:

- The exposure dose of $1 \mathrm{X}$-ray for biological tissue corresponds (equivalent) to an absorbed dose of $1 \mathrm{rad}$ and an equivalent dose of $1 \mathrm{rem}$ (at $K=1$ ).

- Roughly speaking, the units $1 \mathrm{R}, 1 \mathrm{rad}$ and $1 \mathrm{rem}$ are equivalent to each other. Sievert (Sv) is a derived unit of ionising radiation dose per International System of Units (SI) and is a measure of the health effect of low levels of ionising radiation on the human body.

$1 \mathrm{~Sv}$ equals to the physical quantity called "absorbed dose", which is measured by the unit Gray (Gy):

$$
1 \mathrm{SV}=1 \mathrm{~Gy} . K=1 \mathrm{~J} / \mathrm{kg} . K=100 \mathrm{RAD} K=100 \text { REM, }
$$

when $K=1$ (for x-rays, $\gamma$-rays, $\beta$-radiation, electrons and positrons), $1 \mathrm{~Sv}$ corresponds to the absorbed dose of:

$$
\text { Gy }(1 \mathrm{~Sv}=1 \mathrm{~Gy}=1 \mathrm{~J} / \mathrm{kg}=100 \mathrm{rad}=100 \mathrm{rem})
$$

\subsubsection{Ambient dose equivalent}

For the purposes of routine radiation protection, it is desired to characterise the potential individual's radiation exposure in terms of a single dose equivalent as a quantity that would exist in a phantom approximating the human body. 
"Ambient dose equivalent" $\left(\mathrm{H}^{*}(\mathrm{~d})\right)$ was defined in ICRU Report 51 as "the dose equivalent that would be produced by an expanded and aligned radiation field at a depth $d$ in the ICRU sphere". The recommended reference depths are $10 \mathrm{~mm}$ for strongly penetrating radiation and $0.07 \mathrm{~mm}$ for weakly penetrating radiation, respectively.

As an operational quantity in radiation protection, $\mathrm{H}^{*}(\mathrm{~d})$ shall serve as a conservative and directly measurable estimate of protection quantities, e.g. "effective dose E", which in turn are intended to give an indication of the risks associated with radiation exposure. The situation shows a complexity in radiation environments being composed of a variety of charged and uncharged particles in a broad energetic spectrum. Radiation fields of similarly complex nature are encountered on-board of aircraft and spaceships.

Again, for X-ray, $\gamma$ - and $\beta$-radiation, electrons and positrons, the values of $\mathrm{x}$-ray, RAD and REM, as well as (separately) the values of Gray and Sievert are equal regarding evaluation of human radiation exposure.

\subsection{General effects of radiation on human body}

Historically, the radiology science, studying the impact of ionising radiation on the human body and animals, revealed long-term and reliable statistics on the effects of such radiation, expressed in the possible risks of disease of certain human organs.

General health effects of cosmic radiation on different levels of the human body are shown in Figure 4.

The biological impact of ionising radiation can be relatively divided into two types (Khiznyak, 2003):

- The biological impact effecting primary physical and chemical processes occurred in molecules of live cells and their environment;

- The biological impact effecting secondary processes such as malfunction of various functions of organism due to the disturbed primary physical and/or chemical processes.

Figure 3 "DO-RA.AVIA" radiation monitoring system

- Our team created a prototype of the server component which is a part of the DO-RA device software complex
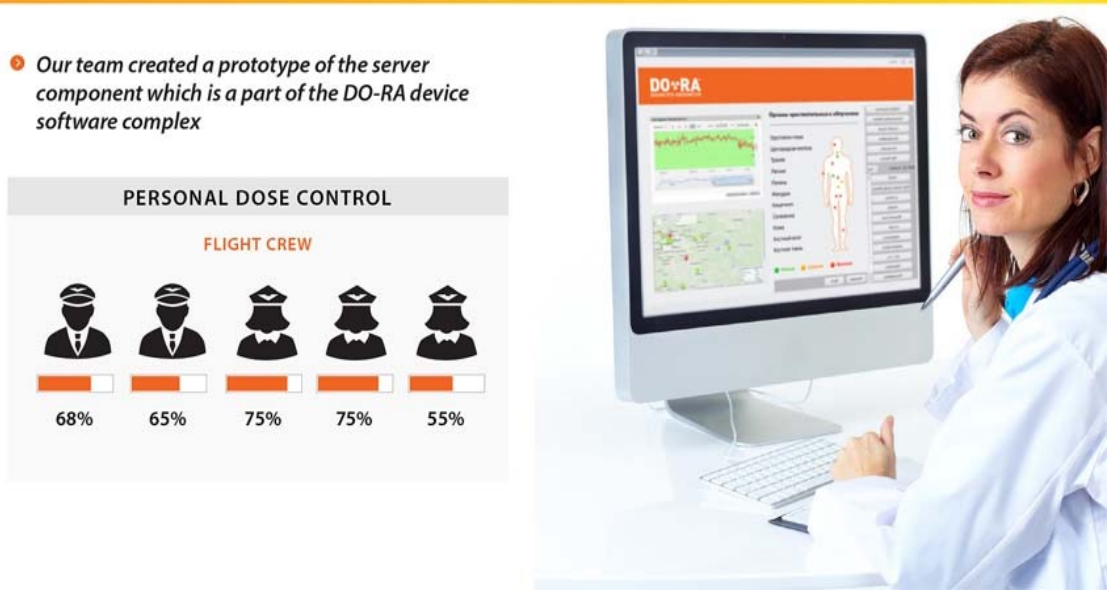
Figure 4 Sensitivity of body organs to radiation

\section{PROBLEM DESCRIPTION}
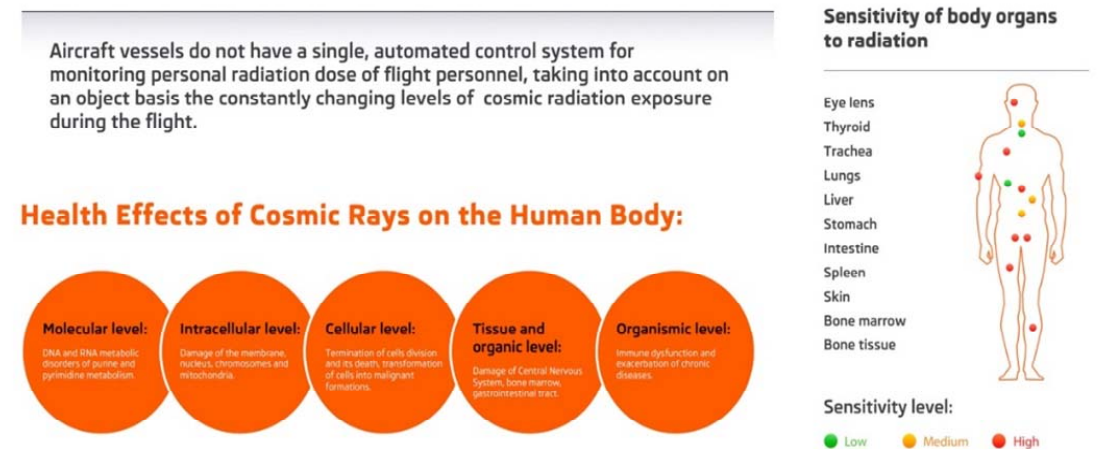

- Low Medium - High

\begin{tabular}{|l|c|}
\hline Human Organ & Coefficient \\
\hline Gonads (Sex Glands) & 0.2 \\
\hline Red bone marrow & 0.12 \\
\hline Large intestine & 0.12 \\
\hline Stomach & 0.12 \\
\hline Lungs & 0.12 \\
\hline Urinary bladder & 0.05 \\
\hline Liver & 0.05 \\
\hline Esophagus & 0.05 \\
\hline Thyroid & 0.05 \\
\hline Skin (epidermis) & 0.01 \\
\hline Cells (bones) & 0.01 \\
\hline Brain & 0.025 \\
\hline Other tissues & 0.05 \\
\hline TOTAL Whole Body & 1 \\
\hline
\end{tabular}

\section{Sensitivity:}

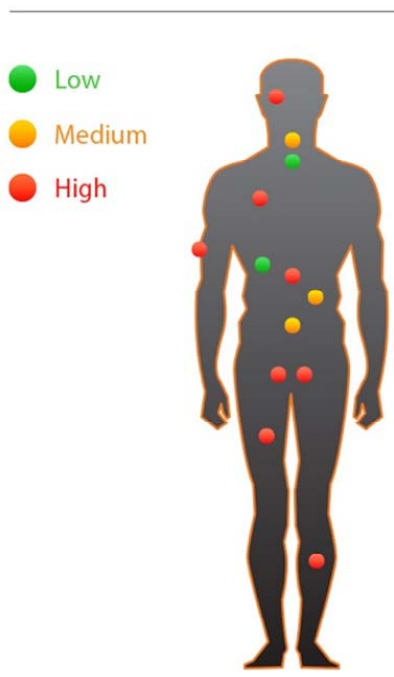

The absorbed energy (from different types of ionising radiation) results in the ionisation of atoms and molecules with subsequent formation of free radicals. Such particles and radicals are highly reactive and can initiate chemical chain reactions. This will also affect the radiolysis of water environment of biological objects. Fast and excessive oxidation process, destruction of molecules, undesired substitution reactions, and other harmful processes may occur because of radiation impact. The DNA molecules are highly sensitive and most vulnerable regarding radiation risks and effects. The DNA molecules are subject to breakage of its various chemical bonds. Such molecule becomes dysfunctional and oncogenic. 
The radiation effects are classified as follows:

- The probable-type effects

- Determined-type effects

The oncological impact considered to be "probable-type effect", it will become more likely that oncological condition would occur the more dose of radiation exposure a person may obtain.

On the other hand, radiation sickness, infertility and cataracts due to radiation, radiation skin damage, anomalies during pregnancy, etc. are all "determined-types" effects of radiation.

Such effects are caused by certain radiation doses. The higher radiation exposure, the more severe and more frequent is radiation impact on human health, especially, considering bio-accumulative effects. The effects of radiation exposure depend on type of radiation, radiation dose during exposure, time of radiation exposure, what organs and parts of human body were exposed to radiation. The radiation sickness (disease) occurs at radon dose $1 \mathrm{~Sv}$. However, people with compromised immune system, pregnant women, children and elderly may incur such severe radiation effects faster and their radiation impact may be more severe compared to healthy adults. Receiving access of 3-5 Sv, 50\% of humans would die without appropriate treatment, mostly because of damage of their brain marrow cells. A human will die within 1-2 weeks at $10 \mathrm{~Sv}$ radiation dose, mostly because of damage to gastrointestinal tract. Upon receiving radiation dose at approximately $100 \mathrm{~Sv}$ humans will die within few days or even within hours because of damage to central nervous system.

At small radiation doses such as $0.2 \mathrm{~Sv}$ or less, "the determined-types" of radiation effects are of lesser concern vs. "probable-types" of effects. The radiation exposure during pregnancy even during medical procedures may result in teratogenic effect (Morozova et al., 2014). The impact of small doses of radiation on human health yet to be further investigated and various studies regarding small doses of radiations and their impact on human body must continue.

\subsection{Radiation safety norms, including Russian federation's NRB-99/2009}

Completing our short introduction into aspects of ionising radiation, we would like to note that due to the active and negative impact of ionising radiation on the human body and its organs (and immune system), special radiation standards, especially, national, for the flight personnel have been introduced into aviation. These rules limit the flights of the aircraft crew at the rate of maximum 80 flight hours per month, maximum 240 flight hours per quarter and maximum 800 flight hours per year per person.

The above flight time norms are taken from "The Order of the Ministry of Transport of the Russian Federation No. 139 of November 21, 2015", which has been drafted in accordance with "The ICAO International Standards and Recommended Practices" ("SARPs"), paragraph 7.6:

"The standards of flight and service flight time for the flight crew members are determined by the standards of the State Aviation Agencies of the countries participants of the ICAO".

However, such an hourly counting of the flight hours nowadays looks archaic as a means to control a total radiation exposure of the flight crew members. 
It is one thing to fly parallel to the Equator over the most populated European or Asian continents and quite another thing to make air travel across the poles. And even more so, it is more dangerous and, thus, should be more problematic for the health to fly during possible solar storms. At such time, when flying, the power of the equivalent dose of the flight crew (and passengers) may differ significantly and do not match with the real norms regarding average flight hours and typical flight.

The data regarding certain disease risks has been taken from the official document “Russian Federation's Radiation Safety Norms NRB 99/2009" (see Figure 4).

Russian Federation has two other basic legislative documents that regulate matters of radiation exposure and handling of radiation materials: FB \#3 dated 01.09.1996 "Regarding Radiation Safety of General Public" and OSPORB-99 "Main Sanitary Regulations Regarding Radiation Safety".

In the Russian Federation the environmental dose rate of radiation background is as follows:

- $\quad$ Normal level $0.08-0.34 \mu \mathrm{Sv} / \mathrm{h}$;

- Allowable background $0.32-0.72 \mu \mathrm{Sv} / \mathrm{h}$;

- Increased background $0.72-1.2 \mu \mathrm{Sv} / \mathrm{h}$;

- Annual radiation dose for the population of the Russian Federation is $2 \mu \mathrm{Sv}$ per year.

According to Russia's regulations an annual effective dose for any professional received by a person from any natural source shall not exceed $5 \mathrm{mSv}$.

\subsection{International norms and regulations including those pertaining to cosmic radiation}

The International Commission on Radiological Protection (ICRP) collects and analyses various data, scientific facts and evidence in the area of radiological protection against ionising radiation. The ICRP also develops and periodically issues their recommendations.

The International Atomic Energy Agency (IAEA) also develops various norms regarding radiation and recommendations as to ionising radiation and how to work with and regulate radioactive substances, materials and objects.

Both organisations provide necessary expertise and assistance to countries and other organisations and companies.

The so-called "NUSS" norms (Nuclear Safety Standards) are recommended rather than mandatory norms. Many countries, including Russian Federation evaluate and mostly accept and follow such "NUSS" norms within their corresponding national regulations.

According to "NUSS" norms an average median effective dose for general population is $1 \mathrm{mSV}$ per year obtained for any five consequent years but it should be no more than 5 $\mathrm{mSv}$.

An individual level of effective dose of radiation per year:

- High concern-over $100 \mathrm{mSv}$

- Increased level-tens of $\mathrm{mSv}$

- Low level-1-10 mSV

- Very low-less than $1 \mathrm{mSv}$

- Negligent-less than $0.01 \mathrm{mSv}$ 
According to publication 60 of ICRP it is recommended to consider cosmic radiation as a part of total radiation obtained by professional pilots.

The practical strategies to control radiation exposure during flight are as follows:

- Limits regarding flight hours.

- Selection of flight routes to minimise radiation exposure.

- Prognosis of radiation during flight.

- Individual monitoring and control of radiation dose obtained during flight.

- Individual and control of accumulative total radiation dose per year as well as for longer periods of time.

- Avoidance of flying engagement by pregnant females.

- Continued weather and other geophysical regarding "cosmic weather" monitoring by national services and accessibility of such data to airlines services. This should include cosmic radiation, magnetic field of earth and sun activity conditions.

- Use of specialized software for calculation of flight condition prognosis.

\subsection{Civil flight statistics and studies regarding radiation impact on flight personnel}

International civil aviation statistics provide the following facts:

- In 2016, the world aviation transported 3.7 billion passengers, with all airlines of the world committed 10 billion flight hours (ICAO and ATOR statistics).

- There are civil flights growth forecasts by 4.6\% per year until 2034 (UAC data). Although even in 2016 air transportation increased by 6\% (ICAO and ATOR statistics).

- In 2017, a record number of passengers were transported on regular flights worldwide - more than 4 billion people, which is on 7\% higher than in 2016, when there was also a significant increase in relation to the previous period.

- At the same time, there are more than 70 million people flying more than 30 times per year according to the ICAO statistics of frequent flyers.

The oncology events may occur in humans with probability coefficient $0.05 \mathrm{~Sv}-1$ when one exposed radiation dose to above $0.02 \mathrm{~Sv}$.

Flight personnel has been subjected to cosmic radiation during their flights. The annual effective dose of radiation for flight personnel is estimated within $2-5 \mathrm{mSv}$, reaching of total radiation amount of $75 \mathrm{mSv}$ at the end of their flight career. Several studies conducted to determine correlation between small doses of radiation obtained by personnel during commercial flights and various health conditions such as oncological, cardiovascular and central nervous system diseases. The radiation doses obtained by human studies mostly were not measured directly.

In German study (Frasch et al., 2009 Report) of their pilots it was established that the frequency of central nervous system cancer among pilots has increased the longer pilots served their airlines. According to this study the flight personnel belong to a professional group with higher risks of receiving annually harmful radiation doses $(8.6 \mathrm{mSv})$. The risk 
regarding prostate cancer was estimated to increase $50 \%$ in pilots. The total radiation dose at the end of pilot's career was calculated not to exceed $100 \mathrm{mSv}$.

The cohort of 6000 pilots was studied between 1960 and 2004 (Hammer et al., 2012). Per this study 127 members of flight personnel died of cancer among total of 405 deaths. A positive correlation between doses of radiation and cancer deaths was established.

Icelandic study (Rafnsson et al., 2005a) has determined that the cosmic rays increase risks of getting so-called "nuclear cataract" among pilots of commercial airlines. The correlation of probabilities among pilots and control group ("non-pilots") was 3.02 (at 95\% confidence interval level,1.44-6.35).

In another study (Rafnsson et al., 2000b) 458 pilots of commercial Iceland's airlines were studied, including those who have been engaged in international flights. The standard coefficient for obtaining cancer was 0.97 at $95 \%$ confidence interval of $0.62-$ 1.46. This coefficient was 1.16 at confidence interval $0.7-1.81$ ) for those pilots who participated in international flights. The standard coefficient for melanoma was 10.20 at 95\% confidence of 3.29-23.81. For commercial pilots of Islandic airlines involved in international flights such coefficient became 15.63 at 95\% confidence interval of 5.0436.46. Analysis and comparison between results of groups and sub-groups established direct dependency between number of flight hours, radiation dose obtained during flights and frequency of melanoma occurrence. Furthermore, researchers observed that an occurrence of melanoma happened to appear more frequent among those pilots who also had to cross 5-time zones during their flights' assignments.

Owing to their professional engagement, commercial pilots are prone to be exposed to elevated doses of cosmic radiation, but the impact of cosmic radiation with regards to DNA damage (translocation) is yet to be further investigated. Researchers (Rafnsson et al., 2000b) studied DNA translocation in a group of commercial pilots having different numbers of flight hours. This study demonstrated an increase in frequency of translocations occurrence for those pilots who had more flight hours:

- Pilots with 1-year flights:

○ coefficient 1.06 at $95 \%$ confidence interval of $1.01-1.11$

- Pilots with higher flight numbers within their 10-year career:

- coefficient 1.81 at $95 \%$ confidence interval of $1.16-2.82$.

Based on experimental results researchers concluded that "aviation's veterans" with larger number of flight hours have higher risks for both cancer occurrence as well as DNA translocations.

\section{3 "DO-RA" technology and "DO-RA.Avia" in-flight personal radiation dosimeter to measure radiation exposure during a commercial flight}

\subsection{Types of radiation measurement devices (dosimeters)}

The method of registration of ionising radiation is a basis for classification for detectors of radiation. Radiation detectors are classified as follows:

- Ionisation detectors:

○ Ionisation cameras

- Gas discharge registration devices (proportional, Geiger-Muller, etc.) 
○ Liquid ionisation cameras, bubble cameras and detectors

○ Semiconductor detectors, crystalline detectors and photodetectors

- Radioluminescent detectors

- Cherenkov's detectors

- Chemical detectors

- Emission detectors

- Calorimetric detector

- $\quad$ Radio-defect detectors

- Activation-based detectors

The detail description of in-flight and other radiation detectors can be found in the article (Morozova et al., 2014).

The most sensitive and compact are semiconductor detectors.

\section{2. "DO-RA” radiation measurement platform}

Our group has developed and patented in various countries an innovative radiation measurement platform technology under general name "DO-RA technology" and corresponding family of semiconductor devices for measurement of the obtained dose of radiation and the total radiation:

- Matrix, solid state detectors of radiation with the PIN diode structure;

- Electronics reading based on discrete components or ASIC chip;

- The device has a Wireless Communications Transfer Protocol;

- Software for the various operational systems;

- Design documentation in international IPC format;

- All devices are combined into a single system based on a server solution.

The "DO-RA" platform technology provides potential users an advanced semiconductor device "DO-RA.AVIA" for use as a personal radiation dosimeter by the flight crew and passengers and as "on-board radiation measurement device".

The "DO-RA.AVIA" device currently has the following technical characteristics:

- Dimensions $(W \times D \times H), \mathrm{mm}: 29.1 \times 7 \times 62$;

- Operating Temperatures: up to $+55^{\circ} \mathrm{C}$;

- Sensor Type: self-generated silicon detector "DoRaSi";

- $\quad \gamma$-and $\beta$-radiation detection: detected;

- Maximum error: $+/-10 \%$ after 60 seconds of measuring;

- Data Transfer Interface: Bluetooth Low Energy (BLE);

- Measuring range of ionising radiation using "DO-RA.Avia" module:

○ Alpha, $15 \mathrm{KeV}-10 \mathrm{MeV}$ energy using "DoRaSi” detector via mica window;

○ Betta, $15 \mathrm{KeV}-10 \mathrm{MeV}$ energy using "DoRaSi” detector with metallic screen; 
○ Gamma, $15 \mathrm{KeV}-10 \mathrm{MeV}$ energy using "DoRaSi" detector with metallic screen;

○ X-Ray, $15 \mathrm{KeV}-10 \mathrm{MeV}$ energy using DoRaSi detector with metallic screen.

- Supported mobile operating systems: Apple iOS, Google Android 2.x, 3.x,4.x, WP, Java ME; and OC: Windows, Linux, Mac OS.

The "DoRaSi" detector has the following characteristics:

- Available dimensions of "DoRaSi" solid-state detector:

a) $0.1 \mathrm{~cm} \times 0.1 \mathrm{~cm}=1.0 \mathrm{~cm}^{2}$;

b) $0.07 \mathrm{~cm} \times 0.07 \mathrm{~cm}=0.5 \mathrm{~cm}^{2}$;

- Measuring range of ionising radiation using "DO-RA.Avia device": see above;

- Error in measuring the dose rate of ionising radiation: $+/-10 \%$ with $t>60 \mathrm{sec}$;

- ASIC Specifications:

○ Chip dimensions: $3.5 \times 2 \mathrm{~mm}^{2}$;

○ Power supply voltage: $1.8 \mathrm{~V}$;

○ Number of channels: 32 ;

- Static power per channel depends on setting: $100 \mathrm{~mW}$;

- Total expected power consumption of the chip: $<15 \mathrm{~mW}$;

○ Operating frequency - data in/out: 10s MHz;

○ Operating frequency - ToT (adjustable): $240 \mathrm{MHz}$, (default) at VBIAS $=1.2$.

The "DO-RA" devices are served by an advanced software and software solutions, including smart phone applications developed by the company and our partners:

- The "DO-RA.AVIA" device software has been developed;

- The software keeps records for each individual user and of the number of users;

- Maintenance of the system operational protocol (self-monitoring);

- Device self-diagnostics, including control of the stored data volume, time and load characteristics control, the number of processed requests, the number of erroneous requests, etc.;

- Receiving data from registered mobile devices with reference to coordinates, heights and time of measurement;

- Long-term storage of measured results;

- Updating the map of radiation monitoring data;

- Providing data monitoring system in the form of maps;

- Provision of REST API to external information systems for access to data collection and storage systems, and data processing system. 
- The platform technology "DO-RA" has over 89 patents (inventions and utility models), certificates for software codes, including USA, Russia, EurAsEC, Japan, Korea, China, India and EU:

○ US 9547089 B2; US 8738077 B2;

○ Korean: 20-0479248;

○ CN $2033537453 \mathrm{U}$

○ JP 3189486;

○ Russian Federation patents: RU № 109625 ; 124101; 116296; 116725; 117226; 2484554; 133943; 136194; 140489; 88973; 156901; 156906; 156907; 145480; 2545502; 159972; 125008; 126484; 2575939; 167308;

○ CIS patents № $025350 ; 74126 ; 14797$.

\subsubsection{Above are only stars: The DO-RA in-flight project}

During many flights around the world, we explored our innovative platform technology "DO-RA" and ran field tests regarding uses of platform "DO-RA" technology in the field of aviation and environmental radiation monitoring.

Figure 5 DO-RA.AVIA dosimeter on-board of commercial flight Moscow-Southern Russia

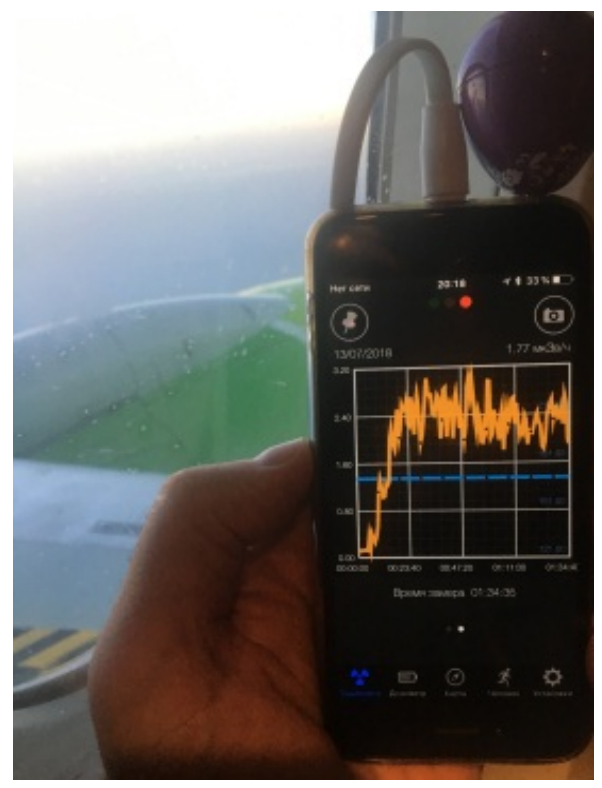

We made measurements regarding level of ionising radiation received by an individual during a flight, using "DO-RA.AVIA" device (personal total radiation dosimeter) and corresponding software.

The results regarding one such flight are summarised herein below:

Route Moscow (Domodedovo)-Southern Russia 
On June 22, 2018 our Project Leader Dr. Vladimir Elin took a flight from Moscow, airport Domodedovo to a city located on the Black Sea of Southern Russia.

A flight took about 2 hours. He has measured his personal exposure to the total radiation during a flight as follows: for radiation measurements Dr. Elin used his Apple iPhone equipped with "DO-RA.Aviation" module and corresponding software (application) accessible at Apple Store, Google Play and company's site (http://dora.com). The screen shots were taking from same iOs/Apple iPhone. The results of the radiation measurement are the following:

Figure 6 Cosmic radiation intensity occurred during a commercial flight Moscow-Southern Russia at cruising height $10,750 \mathrm{~m}$ on July 13, 2018

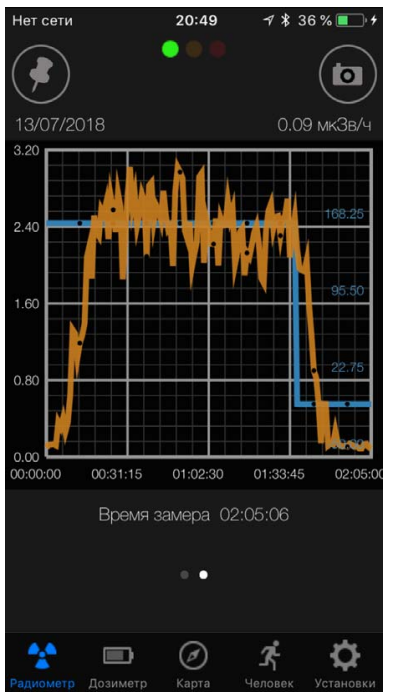

Figure 7 Radiation dose obtained by project leader as a passenger on board of Aeroflot aircraft during his same 2 hour-commercial flight Moscow-Southern Russia

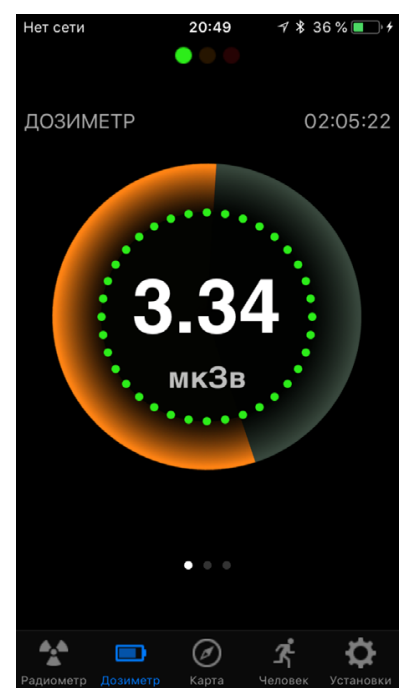


Figure 8 Radiation dose obtained by project leader during his same flight; accumulative radiation dose during current day, month and year

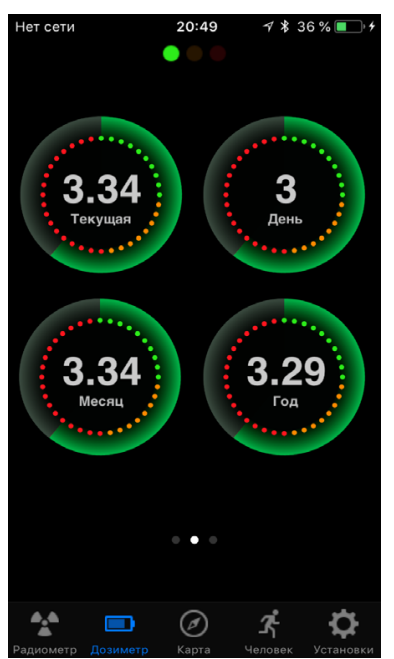

\section{Route Southern Russia-Moscow (Domodedovo)}

On July 13, 2018 our Project Leader Dr. Vladimir Elin took a return flight to Moscow from Southern Russia, located off the Black Sea. A flight took about 2 hours. He has measured his personal exposure to the total radiation during a flight as follows: for radiation measurements Dr. Elin used his Apple iPhone equipped with "DO-RA.AVIA" module and corresponding software (application) accessible at Apple Store, Google Play and company's site (http://do-ra.com). The screen shots were taking from same iOs/Apple iPhone. The results of the radiation measurement are the following:

Figure 9 Cosmic radiation intensity occurred during a commercial flight Southern RussiaMoscow at cruising height 11,600 m on July 22, 2018

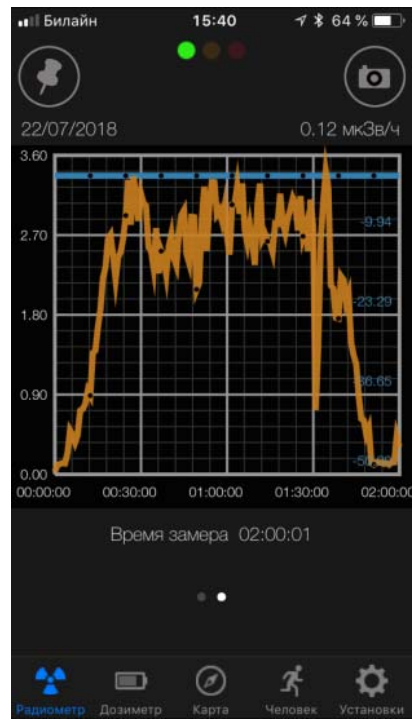


Figure 10 Radiation dose obtained by project leader as a passenger on board of Aeroflot aircraft during his 2 hour-commercial flight Southern Russia-Moscow

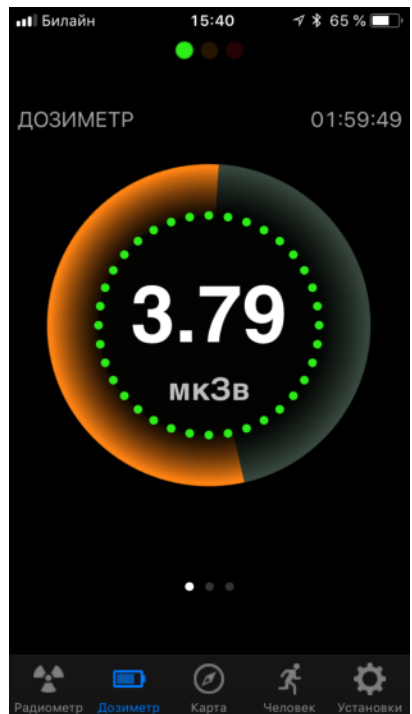

Figure 11 Radiation dose obtained by project leader during a flight; accumulative radiation dose during current day, month and year

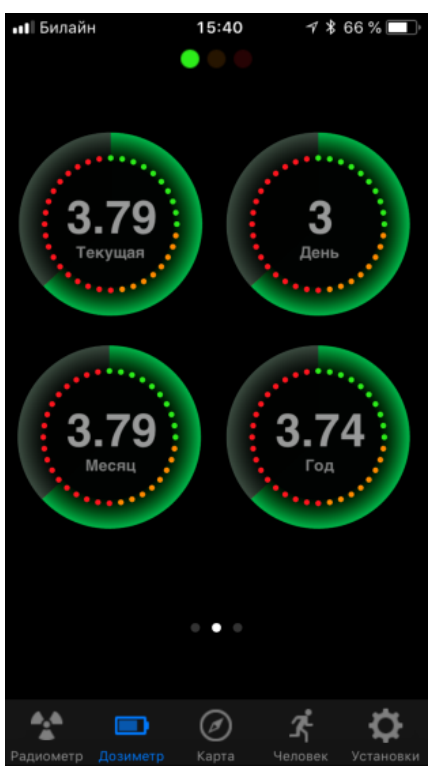

Route Chambery, France-Moscow, Russia (Domodedovo)

- During the take-off of the aircraft in Chambery, France

- the radiation background was $0.10 \mu \mathrm{Sv} / \mathrm{h}$. 
- At the altitude of $3000 \mathrm{~m}$ the background radiation fluctuated between $0.15-0.18 \mu \mathrm{Sv} / \mathrm{h}$.

- At the altitude of $6000 \mathrm{~m}$ the level of background radiation was within $0.30-0.34 \mu \mathrm{Sv} / \mathrm{h}$

- At the altitude of $8800 \mathrm{~m}$ the level of background radiation was already $0.72-0.76 \mu \mathrm{Sv} / \mathrm{h}$.

- At the altitude of $10,100 \mathrm{~m}$ the level of background radiation has risen to $1.02-1.12 \mu \mathrm{Sv} / \mathrm{h}$

- Finally, at the maximum height of the route, namely at the height of $10,700 \mathrm{~m}$ the background radiation was $1.22-1.35 \mu \mathrm{Sv} / \mathrm{h}$.

- When landing in Moscow, Domodedovo airport, all measured data regarding radiation background was confirmed with $100 \%$ accuracy at the same heights.

"DO-RA" dosimeters, and, specifically, "DO-RA.AVIA" have been successfully tested while being deployed with the following platforms and devices:

- Apple iOS platform:

○ iPhone $4 \mathrm{~S}$

○ iPhone 5

○ iPhone $5 \mathrm{~S}$

○ iPhone 5C

○ iPhone 6

$\circ \quad$ iPhone 6-plus

○ iPod Touch 6th

○ $\quad$ iPad 2

○ iPad 3

- iPad Air

○ iPad Mini

○ iPad Mini Retina

- Google Android 4.x platform:

○ Samsung Galaxy S3

○ Samsung Galaxy S4 (9500/9505)

- Samsung Galaxy Note 3 (9005)

- Samsung Galaxy Note Pro

- HTC One (m7) and HTC One dual sim

○ Sony Experia Z2 
○ Sony Z Ultra

- Amazon Kindle Fire HDX

○ Google Nexus 5

- Google Nexus 7

- ZTE LEO S1

○ Huawei Honor 3

○ Motorola Moto g

○ YotaPhone and YotaPhone2

- Google Android 5.x:

- Samsung Galaxy S4 (9500/9505)

○ Samsung Galaxy Note3 (9005) Sony Z Ultra

○ Google Nexus 5

- Google Nexus 7

- Windows phone 8:

- HTC Windows Phone $8 \mathrm{x}$

- Nokia Lumia 925

- Nokia Lumia 1520

- MacBook

- Lenovo Twist

- Smart watches:

- Samsung Galaxy Gear 2 (Android)

- Sony SmartWatch 2 (Android)

- Windows, Linux, Mac OS:

- Apple iMac

○ MacBook Air

- MacBook Pro

○ MacBook

- Lenovo Twist

Software products and software applications are accessible by users on 23 languages.

\section{Conclusions}

The "DO-RA" radiation measurement technology and "DORA.AVIA" dosimeter module incorporated into a smart phone demonstrated a reliable, convenient and precise way to measure a person's individual radiation exposure dose and total radiation which were 
obtained during a 2-hour commercial flight Moscow (Domodedovo)-Southern Russia) and return flight back to Moscow. The radiation dose including cosmic radiation that Project Leader as a passenger obtained during a return flight, was 12\% higher at 11,600 $\mathrm{m}$ cruising height compared to his forward flight cruising at $10,750 \mathrm{~m}$. Thus, the higher cruising height, to the more radiation exposure passengers and flight personnel would be subjected (they would obtain higher dose of radiation at higher cruising heights). Individuals' organs and overall health may differently respond on same radiation doses.

Radiation levels were also measured during commercial flight Chambery, FranceMoscow, Russia (Domodedovo).

During the above flights neither aircraft was equipped with radiation measurement devices accessible by passengers individually to measure their respective individual dose of radiation exposure and total radiation exposure during their flight. The leading flight personnel did not report to passengers any information regarding radiation levels during their flight. Passengers were not aware about radiation levels that they have been exposed to during their flight. Passengers were not informed if an aircraft was equipped with radiation measurement devices. None of the passengers had individual dosimeters to measure their exposure to radiation during a flight, with exception of one passenger ("DO-RA" Project Leader) who has used an innovative "DO-RA.AVIA" device, incorporated into his smart phone to measure his personal radiation dose and total radiation dose obtained during his both flights.

There is an increasing necessity in developing modern advanced and yet inexpensive methods and "in-flight" ("on-board") personal dosimeter devices to measure total exposure of flight personnel and passengers to radiation obtained during their flights. One approach to address the problem of radiation exposure during flight is to use patented innovative platform technology "DO-RA" and its "DO-RA.AVIA" devices to monitor personal radiation dose and total amount of radiation exposure.

Apparently, the market potential for personal devices to monitor individual radiation dose and total radiation is large and ready for steady and stable growth.

However, the use of "DO-RA" platform technology is very diverse in scope since such devices can be deployed in nuclear medicine, nuclear industry, homeland security areas such as nuclear non-proliferation control and to detect radon gas (inside buildings or living spaces and in the drinking water).

Such devices can be installed within cars and commercial vehicles, including car DVRs and navigators.

"DO-RA.AVIA" module and other "DO-RA" modules can find a use in people's households and be integrated into various household appliances and devices, ranging from a refrigerator, air conditioner, TV, including a wide range of items, accessible through internet, drones and video cameras for various types of surveillance.

"DO-RA" dosimeter devices can be deployed in public places, in transport and cargo logistics and security, and can be used on board of space shuttles and international space stations (or as a part of various outer space instruments).

"DO-RA.Watch - DO-RA.AVIA" module integrates both devices into the case of a wrist electronic watch or a radiation detector used in the form of an individual module, incorporated into a watch strap to measure ionising radiation.

"DO-RA" devices can be integrated into LED lighting and security monitoring systems installed in public places, and office buildings. 
Data transmission is carried out via secured wireless protocols and through a secured wired network to the local regional or national corporate "Radiation Monitoring Centre", and federal and other domestic agencies, local and national emergency services, when necessary.

"DO-RA.AVIA" and other "DO-RA" modules can be integrated into wearable equipment of the soldiers for the operational monitoring of the radiation situation in the battlefield and during training in the military deployment areas.

"DO-RA" dosimeter technology (chips and devices) is synergetic to various other advanced platform technologies and instrumentation, such as patented nanomolecular "Spectro-Fluor" optical platform technology (Carbon-Fluorine Isochronic Pulsed Laser Spectroscopy). Incorporation and synergising both technologies into one integrative device can expand capabilities and functionalities of such technologies. As an example, it will allow for simultaneous measurement and control (continuous monitoring) of patient's radiation exposure (individual dose per time interval, and total radiation exposure), thus, assuring appropriate delivery of intended therapeutic doses of fluoroorganic drug or preparation administered to a patient during therapeutic treatments or during medical diagnostic procedures.

Pharmaceutical preparations to mitigate the effects of low dosage radiation exposure and accumulative low-level radiation exposure are not available and yet to be developed. Research in this drug discovery segment and in the area of effects of low-level radiation can be done by using an integrative intellectual system "DORA-Spectro-Fluor" and innovative technology platforms such as "DORA-Spectro-Fluor" (Menaa et al, 2011), a spectrometer having a Nd:YAG pulsed laser, fibre optic probe, ICCD camera, time gating and time delay functions, and an integrated semiconductor radiation detection module "DO-RA".

\section{References}

Frasch, G., Fritzsche, E., Kammerer, L., Karofsky, R., Spiesl, J. and Stegemann, R. (2009) The occupational radiation exposure in Germany 2007 [in German], Report No.: BfS-SG-12/09, Bundesamt fur Strahlenschutz, Salzgitter.

Hammer, G.P., Blettner, M., Langner, I. and Zeeb, H. (2012) 'Cosmic radiation and mortality from cancer among male German airline pilots: extended cohort follow-up', European Journal of Epidemiol, Vol. 27, pp.419-429.

Khiznyak, V. (1990) Careful: Radiation, Krasnoyarsk.

Menaa, F. et al. (2011) 'Fluoro-Raman spectroscopy as a new analytical tool for pharmaceutical and biomedical applications', Faraday Discussions, Vol. 149, pp.269-278. An article in the Book Analysis for Healthcare Diagnostics and Theranostics, PSC Publishers (Royal Society Chemistry), Great Britain, Available online at: https://rive.google.com/file/ d/1ZG0wrg5wcblMrLs8cUBpmRDj0W0GUqDS/view?usp=sharing

Morozova, M., Lapshin, V., Dorensky, C. and Syiroeshkin, A. (2014) 'Flight dosimetry', Geliogeophysical Research, Vol. 10, pp.54-92.

Rafnsson, V., Hrafnkelsson, J. and Tulinius, H. (2000b) 'Incidence of cancer among commercial airline pilots', Occupational and Environmental Medicine, Vol. 57, pp.175-179.

Rafnsson, V., Olafsdottir, E., Hrafnkelsson, J., Sasaki, H., Arnarsson, A. and Jonasson, F. (2005a) 'Cosmic radiation increases the risk of nuclear cataract in airline pilots: a population-based case-control study', Arch Ophthalmology, Vol. 123, pp.1102-1105.

Russian Federation's Radiation Safety Norms (2009) NRB-99/2009. 